\title{
DESEMPENHO DE COLHEDORAS SEMIMONTADAS PARA A COLHEITA DIRETA DE MILHO
}

\author{
CARLOS M. DE LIMA ${ }^{1}$, JOSÉ P. MOLIN², JOÃO C. DE ARAÚJO 3 , \\ MIGUEL A. I. T. DEL PINO
}

\begin{abstract}
RESUMO: O objetivo do trabalho foi adaptar procedimentos de ensaio existentes para colhedoras autopropelidas e avaliar o desempenho de colhedoras semimontadas, de uma e duas fileiras, operando com três velocidades de deslocamento em dois graus de umidade. Para tanto, foi desenvolvido um dispositivo de coleta do material efluente das máquinas, foram analisadas as perdas de plataforma, de separação e limpeza, de trilha e os parâmetros de qualidade: impureza, danos mecânicos dos grãos e falhas na germinação. O delineamento experimental foi em blocos casualizados, dispostos em esquema fatorial 2 x 3, com seis repetições. Não houve efeito dos tratamentos em relação às perdas na colhedora de uma fileira. $\mathrm{Na}$ colhedora de duas fileiras, houve efeito significativo nos fatores, em relação a todas as perdas, exceto as perdas de plataforma, apresentando melhores resultados com o menor grau de umidade $(16 \%)$ e a maior velocidade de deslocamento $\left(1,52 \mathrm{~m} \mathrm{~s}^{-1}\right)$. Quanto aos indicadores de qualidade, ambas as colhedoras apresentaram melhores resultados com o menor grau de umidade, na menor velocidade de deslocamento. Concluiu-se que o procedimento adotado foi efetivo para a avaliação do desempenho de colhedoras semimontadas de milho, e o sistema desenvolvido para a coleta de material é eficiente, porém é exigente em mão de obra.
\end{abstract}

PALAVRAS-CHAVE: agricultura familiar, mecanização, perdas na colheita.

\section{PERFORMANCE OF SEMI-MOUNTED HARVESTERS FOR CORN HARVESTING}

\begin{abstract}
The objective of this work was to adapt existent testing procedures for self propelled harvesters and to evaluate semi-mounted commercial harvesters of one and two rows, operating at three forward speeds and two grain moistures. A device was designed and adapted to the machines to collect the material other than grain (MOG) and the indicators analyzed were header loss, separation and cleaning loss, and threshing loss and the quality indicators were: impurity, damage and germination failures. The experiment was conducted as a randomized blocks design disposed in factorial outline $2 \times 3$, with six replications. There was no effect of treatments related to the losses for the one row harvester. For the two rows harvester there was significant effect in the grain moisture and speed, in relation to all the losses, except to header losses, presenting better results with the lowest grain moisture $(16 \%)$ and higher forward speed $\left(1.52 \mathrm{~m} \mathrm{~s}^{-1}\right)$. Related to quality indicators, both harvesters presented better results with the lowest grain moisture in the lowest speed. It was noticed that the procedure for evaluating semi-mounted corn harvesters and the device designed to collect the MOG are efficient but exigent on labor demand.
\end{abstract}

KEYWORDS: small farm, mechanization, harvest losses.

\footnotetext{
${ }^{1}$ Licenciado em Ciências Agrárias, Mestrando, ESALQ/USP, Piracicaba - SP, Fone: (0XX35) 9819.9571, cmlmagno@gmail.com

${ }^{2}$ Eng $^{\circ}$ Agrícola, Professor Associado, ESALQ/USP, Piracicaba - SP.

${ }^{3}$ Eng ${ }^{0}$ Agrônomo, Professor Doutor, EAFI, Inconfidentes - MG.

${ }^{4}$ Eng ${ }^{\circ}$ Agrícola, Professor Doutor, EAFI, Inconfidentes - MG.

Recebido pelo Conselho Editorial em: 1은 $2-2008$
}

Aprovado pelo Conselho Editorial em: 3-10-2008 


\section{INTRODUÇÃO}

O milho (Zea mays, L.) é uma das culturas mais importantes do mundo, com produção projetada para a safra 2007/2008 de 777 milhões de toneladas. O maior produtor mundial são os EUA, seguido pela China e pelo Brasil, com produções projetadas de 326; 148 e 50 milhões de toneladas, respectivamente (CIMILHO, 2007). A produção nacional, segundo estimativas da CONAB (2007), para a safra 2007/2008, tem como maior produtor o Paraná, seguido por Minas Gerais, Mato Grosso e Rio Grande do Sul, com produções de 13,682; 6,225; 5,898 e 5,547 milhões de toneladas, respectivamente.

Existem diversos fatores que podem influenciar na produtividade da lavoura, sendo a prática da colheita e do transporte, processos críticos, pois, quando mal conduzidos, podem resultar em significativo prejuízo, por causa das perdas, mesmo que a produtividade da cultura tenha sido adequada. A colheita é a última operação desempenhada no campo e tem por objetivo retirar o produto das demais partes do organismo vegetal, em tempo hábil que permita a mínima perda quantitativa e o alcance do nível máximo de qualidade (MIALHE, 1984; SRIVASTAVA et al., 1993).

A colheita mecanizada direta apresenta perdas quantitativas na coleta do material (plataforma) e as causadas pelos mecanismos internos da colhedora, altamente influenciadas pela taxa de alimentação da máquina e das condições da cultura no momento da colheita (SOUZA et al., 2006). Apresenta, também, perdas qualitativas, tais como: impurezas nos grãos colhidos, danos mecânicos e falhas na germinação, importantes quando se trata da colheita de sementes.

A umidade dos grãos fora das condições ideais de colheita, as regulagens incorretas e a velocidade inadequada de deslocamento da colhedora são responsáveis por elevados índices de perdas de grãos. A minimização de perdas na colheita para um patamar aceitável pode ser obtida por meio do treinamento adequado dos operadores, da apropriada manutenção das colhedoras, da eficiente regulagem das máquinas, da escolha da correta velocidade de trabalho e da operação da colheita no momento adequado (BALASTREIRE, 1987).

A caracterização do desempenho de uma colhedora é fundamentada nas perdas de grãos decorrentes das diferentes condições operacionais (KYDD, 1980). No mercado brasileiro, são disponíveis colhedoras semimontadas de milho, utilizadas por pequenos e médios produtores, que não dispõem de informação relacionada às reais condições operacionais dessas máquinas. Sendo assim, o presente trabalho teve como objetivo adaptar procedimentos de ensaio existentes para colhedoras autopropelidas e avaliar o desempenho de colhedoras semimontadas de uma e de duas fileiras quanto aos aspectos de perdas quantitativas e qualitativas.

\section{MATERIAL E MÉTODOS}

Por não existirem normas específicas para ensaio de colhedora semimontada, foi adotada como referência a norma NBR 9740 (ABNT, 1987), adaptando-a às condições das colhedoras ensaiadas. Foram utilizadas duas colhedoras marca Jumil: modelo JM-350, semimontada, com sistema de fluxo axial, posicionada lateralmente em relação ao trator, que colhe apenas uma fileira de plantas por vez, aqui denominada de $\mathrm{C} 1$; modelo JM-380, com características semelhantes à anterior, com capacidade de colher duas fileiras por vez, denominada de C2. São constituídas por sistema de recolhimento, de alimentação, de trilha e separação e de limpeza, e foram acopladas aos tratores na barra de tração e no chassi, localizando-se à direita e atrás dos mesmos.

$\mathrm{O}$ acionamento e o transporte da colhedora $\mathrm{C} 1$ foram realizados por um trator Massey Ferguson, modelo MF 275, com tração dianteira auxiliar (TDA), equipado com motor diesel de $56,0 \mathrm{~kW}(76 \mathrm{cv})$ de potência. Para a colhedora C2, utilizou-se de um trator Massey Ferguson, MF 283 TDA, com 63,3 kW (86 cv) de potência.

Os experimentos foram realizados na Fazenda Experimental da Escola Agrotécnica Federal de Inconfidentes, no município de Inconfidentes - MG. As áreas experimentais situam-se na latitude 
$22^{\circ} 18^{\prime} \mathrm{S}$, longitude $46^{\circ} 19^{\prime} \mathrm{W}$, altitude média de $855 \mathrm{~m}$, apresentando declividades médias de $1 \%$, sendo o regime pluviométrico médio do local de $1.500 \mathrm{~mm}$ por ano. Segundo PRADO (2005), o solo da área classifica-se como Argissolo Acinzentado eutrófico.

Foi utilizado o milho híbrido triplo, de ciclo superprecoce (DEKALB 455), adaptado a várias regiões do Brasil, com as seguintes características, segundo seu fornecedor: tipo e cor do grão duro/alaranjado; soma térmica - 715 U.C.; florescimento masculino médio - 60 dias; maturação fisiológica média - 120 dias; altura média da planta - 2,3 m; inserção média da espiga superior $1,10 \mathrm{~m}$; "stay green" - acentuado; empalhamento bom. A semeadura foi realizada no dia 10-112005, no sistema convencional, em área de aproximadamente 3 ha, com população final esperada de 55.000 plantas ha $^{-1}$, com espaçamento entre fileiras de $0,8 \mathrm{~m}$.

Inicialmente, as colhedoras foram reguladas por engenheiros da fábrica designados para acompanhar o ensaio. As colheitas foram realizadas nos dias 19-4-2006 e 24-4-2006, a partir do monitoramento do grau de umidade dos grãos na lavoura, respectivamente, de 22 e $16 \%$. Na área experimental, foram determinadas 108 fileiras de milho com comprimento de $40 \mathrm{~m}$ cada, sendo 36 fileiras para serem colhidas com a colhedora $\mathrm{C} 1$, e 72 fileiras para a colhedora $\mathrm{C} 2$, todas com bordaduras de $20 \mathrm{~m}$ para atender ao tempo de enchimento da colhedora. Foram coletados a palha e os grãos de milho processados pelas colhedoras, além da coleta manual das espigas que não entraram na máquina.

Para facilitar a coleta do material, foi desenvolvido um sistema que permitiu coletar toda a palha proveniente da saída da colhedora, que consistiu de reservatório que foi instalado na sua lateral, com dimensões que comportaram e armazenaram o volume de palha correspondente à parcela. Também foi desenvolvido um direcionador de fluxo, fazendo a conexão entre a saída de palha da colhedora e o reservatório, com dimensões que não promoveram o estrangulamento do mesmo e não interferiram no processamento (Figura 1). Esse mecanismo facilitou a operação de coleta nas parcelas e o descarte nas bordaduras. O reservatório foi revestido com chapa metálica lisa, com os cantos arredondados na sua parte inferior e telado na parte superior, para permitir a saída do ar (Figura 1). O reservatório de palhas para a colhedora $\mathrm{C} 2$ foi ampliado em função de a quantidade de massa ser o dobro daquela produzida pela colhedora C1. Essa ampliação consistiu no alongamento do reservatório, utilizando um saco telado colocado no final do sistema (Figura 1). Dispositivo semelhante foi utilizado em ensaio realizado por KYDD (1980), com colhedoras automotrizes, na colheita de grãos (cevada e trigo).

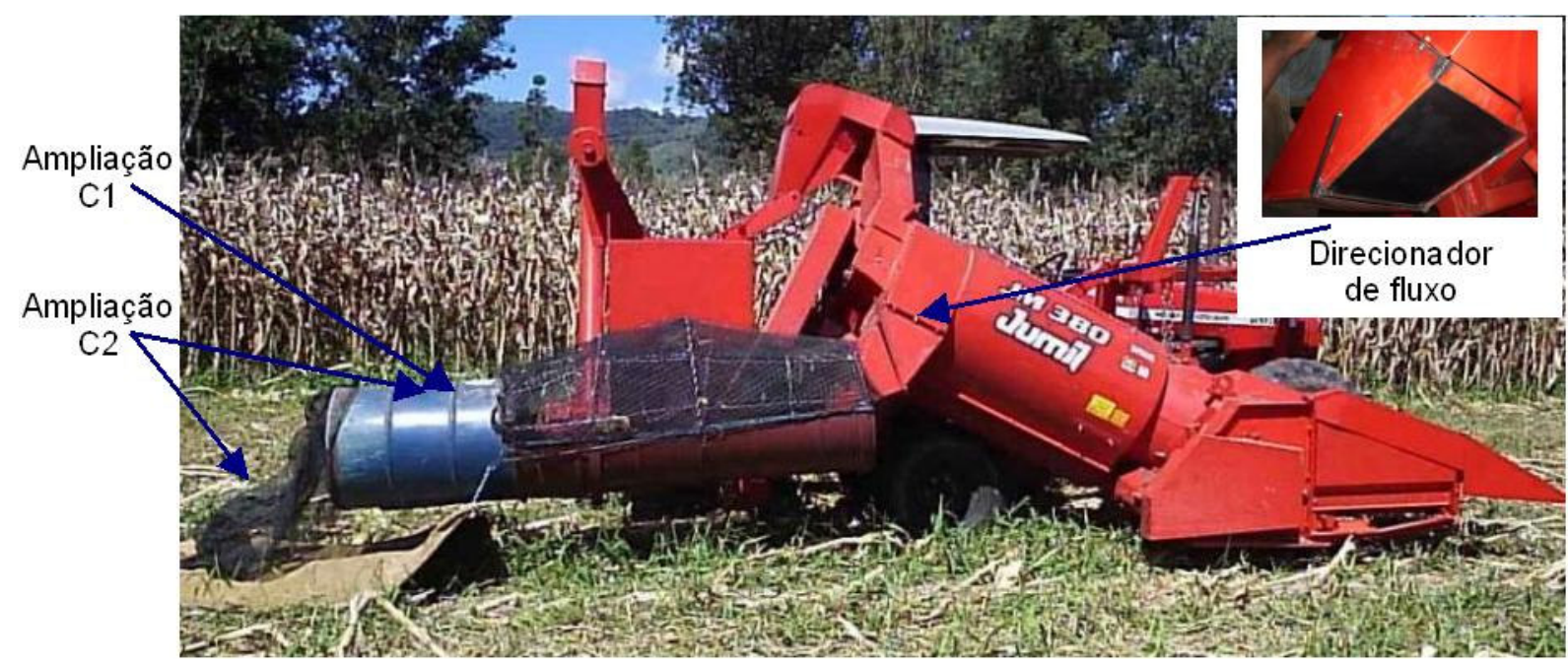

FIGURA 1. Vista lateral do reservatório de palha da colhedora C2 com detalhes do direcionador de fluxo e das ampliações para as colhedoras $\mathrm{C} 1$ e $\mathrm{C} 2$. Lateral view of the straw compartment of $\mathrm{C} 2$ harvester with details of the flow guiding and the enlargements for the harvester $\mathrm{C} 1$ and $\mathrm{C} 2$. 
Antes de iniciar a colheita, uma equipe percorreu a fileira de cada parcela para coletar as espigas caídas e tombadas, atribuindo essa a perdas de pré-colheita. Após a passagem da colhedora, a mesma equipe percorreu as parcelas coletando as espigas caídas no chão. Já grãos caídos foram mensurados por amostragem com o auxílio de armação retangular, com dimensões de $1,0 \mathrm{~m} \mathrm{x}$ $0,8 \mathrm{~m}$, para a colhedora $\mathrm{C} 1$, e de $1 \mathrm{~m} \times 1,6 \mathrm{~m}$, para a colhedora $\mathrm{C} 2$. A largura da armação foi determinada de acordo com a plataforma de cada colhedora, e foram coletados os grãos encontrados no interior das mesmas. Esses, somados aos grãos encontrados nas espigas, determinaram as perdas de plataforma. BEDUSCHI (1986) utilizou esse mesmo dispositivo, porém com dimensões diferentes. A partir das espigas e dos grãos coletados, a perda ocorrida na plataforma recolhedora pôde, então, ser determinada.

Ao final de colheita de cada fileira, os grãos de milho foram coletados e acondicionados em sacos de polietileno e pesados. De cada saco foram coletadas amostras de $1,2 \mathrm{~kg}$ para posterior análise em laboratório. Foram avaliadas as impurezas nos grãos, grau de umidade dos grãos, danos mecânicos e falhas na germinação. A palha proveniente da colheita de cada parcela foi retirada e acondicionada em encerado de polietileno com dimensões de $3 \mathrm{~m} \mathrm{x} 4 \mathrm{~m}$ e, em seguida, a mesma foi pesada e abanada manualmente, utilizando peneiras teladas (malha 5), sendo os grãos resultantes separados e acondicionados em sacos plásticos. Os grãos presos aos sabugos também foram debulhados manualmente e armazenados em sacos plásticos, determinando, assim, as perdas de trilha, separação e limpeza. Amostras de espigas foram coletadas na área de bordadura de cada bloco de colheita para servirem como testemunhas às análises de laboratório, sendo posteriormente debulhadas à mão.

Para a realização de todas as tarefas de campo, foram necessárias 14 pessoas para cada colhedora, distribuídas da seguinte maneira: duas para perdas de pré-colheita; duas para plataforma; uma para o direcionador de fluxo; uma para a bica de ensaque; duas para a retirada de palha do reservatório; duas para o transporte do material; uma para cronometrar a velocidade de deslocamento da colhedora; um operador; duas para pesagem e anotações. Para processar o material e os dados coletados no campo, foram necessárias apenas duas pessoas, para as duas colhedoras.

O experimento foi realizado com três velocidades de deslocamento, aferidas com cronômetro, distribuídas aleatoriamente para as fileiras de cada parcela. As marchas utilizadas nos tratores foram: primeira reduzida, segunda reduzida e terceira reduzida, resultando nas velocidades de $0,53 \mathrm{~m} \mathrm{~s}^{-1}, 0,77 \mathrm{~m} \mathrm{~s}^{-1}$ e $1,42 \mathrm{~m} \mathrm{~s}^{-1}$ no trator modelo MF 275 , e $0,59 \mathrm{~m} \mathrm{~s}^{-1}, 0,85 \mathrm{~m} \mathrm{~s}^{-1}$ e $1,52 \mathrm{~m} \mathrm{~s}^{-1}$, no trator modelo MF 283, mantendo-se a rotação da TDP em 540 rpm.

O grau de umidade dos grãos foi determinado segundo a metodologia descrita por BRASIL (1992). Para a determinação dos danos mecânicos, utilizou-se de amostra contendo 100 grãos para cada parcela, obtida após homogeneização e divisão em um divisor de amostras de solo. As amostras foram imersas durante 5 minutos em solução de iodo a $0,08 \%$, preparada pela diluição de uma tintura de iodo 2,0\%. A presença de fragmentos e trincas nos grãos foi verificada pela coloração escura (marrom-azulada) resultante da reação entre o iodo e o amido do endosperma, sendo os resultados expressos em percentagem de grãos danificados (SATO, 1991). O teste de germinação foi conduzido de acordo com as normas para Análise de Sementes (BRASIL, 1992). Os testes de pureza física foram realizados de acordo com as Regras de Análises de Sementes (BRASIL, 1992), e para o cálculo das impurezas pesaram-se todas as partículas presentes na amostra, bem como os grãos defeituosos, fragmentos e a presença de sementes de outras espécies. A percentagem da pureza foi determinada pela relação entre a massa dos grãos e a massa total da amostra.

Foi empregado o delineamento fatorial $2 \times 3$ (dois graus de umidade dos grãos e três velocidades de deslocamento da colhedora), com seis repetições. Todos os dados obtidos foram submetidos à análise estatística, utilizando o programa SISVAR 4.6 (FERREIRA, 2000), empregando-se a análise de variância, com aplicação do teste F. Os dados de perdas, em percentagem, foram transformados em arco-seno da raiz quadrada de $\mathrm{x} / 100$. As comparações das 
médias dos tratamentos com as duas épocas de colheita (grau de umidade dos grãos) e as três velocidades de deslocamento da colhedora foram realizadas aplicando-se o teste de Tukey, com nível de significância de 5\%.

\section{RESULTADOS E DISCUSSÃO}

A metodologia referente à adaptação das normas da ABNT permitiu a coleta dos dados e a avaliação das colhedoras. O percurso necessário para estabilizar a velocidade e o fluxo de grãos e palha dentro da colhedora foi reduzido de $50 \mathrm{~m}$ (autopropelida) para $20 \mathrm{~m}$ (semimontada). A adaptação feita nas colhedoras para a coleta da palha funcionou perfeitamente, porém o acionamento da alavanca do direcionador de fluxo de palha não ofereceu segurança para o seu operador, sugerindo-se, em futuras oportunidades, modificações que solucionem esse problema. A coleta de todo o material processado pela colhedora proporcionou a obtenção de dados reais e não estimados por amostras, possibilitando, assim, reduzir erros experimentais em função da possível variabilidade espacial entre as parcelas. No entanto, o método demonstrou demandar elevada quantidade de pessoas envolvidas na realização de todas as tarefas de campo.

Pelos resultados das análises de variância apresentados na Tabela 1, observa-se que não houve efeito significativo dos fatores para a colhedora $\mathrm{C} 1$. No caso da colhedora $\mathrm{C} 2$, houve efeito dos fatores umidade dos grãos e velocidade de deslocamento para perdas de separação e limpeza, separação e limpeza mais trilha e perdas totais. Para perdas de trilha, houve somente efeito para o fator umidade.

TABELA 1. Análise de variância de perdas de grãos na plataforma, separação e limpeza, trilha, separação e limpeza mais trilha e perdas totais das colhedoras de uma e duas fileiras. Analysis of variance of head grains losses, separation and cleaning, thrashing, separation and cleaning plus thrashing and total losses of the one and two rows harvesters.

\begin{tabular}{|c|c|c|c|c|c|c|}
\hline \multirow{2}{*}{$\begin{array}{l}\text { F.V. } \\
(1)\end{array}$} & \multirow[b]{2}{*}{ G.L.(2) } & \multicolumn{5}{|c|}{ Quadrados Médios - C1 } \\
\hline & & Plataforma & Separação e Limpeza & Trilha & $\begin{array}{c}\text { Separação e Limpeza } \\
\text { + Trilha }\end{array}$ & $\begin{array}{l}\text { Perdas } \\
\text { Totais }\end{array}$ \\
\hline Umidade & 1 & $0,000004^{\mathrm{ns}}$ & $0,002776^{\mathrm{ns}}$ & $0,000651^{\mathrm{ns}}$ & $0,003202^{\mathrm{ns}}$ & $0,003192^{\mathrm{ns}}$ \\
\hline Velocidade & 2 & $0,000006^{\mathrm{ns}}$ & $0,001009^{\mathrm{ns}}$ & $0,000142^{\mathrm{ns}}$ & $0,001059^{\mathrm{ns}}$ & $0,001051^{\mathrm{ns}}$ \\
\hline Interação & 2 & $0,000007^{\mathrm{ns}}$ & $0,001285^{\mathrm{ns}}$ & $0,000048^{\mathrm{ns}}$ & $0,001370^{\mathrm{ns}}$ & $0,001375^{\mathrm{ns}}$ \\
\hline Blocos & 5 & - & - & - & - & - \\
\hline Resíduo & 25 & - & - & - & - & - \\
\hline C.V. (\%) & - & 133,67 & 40,11 & - & 41,93 & 41,87 \\
\hline \multirow[b]{2}{*}{$\begin{array}{l}\text { F.V. } \\
(1)\end{array}$} & \multirow[b]{2}{*}{ G.L. (2) } & \multicolumn{5}{|c|}{ Quadrados Médios - C2 } \\
\hline & & Plataforma & Separação e limpeza & Trilha & $\begin{array}{c}\text { Separação e limpeza } \\
\text { mais trilha }\end{array}$ & $\begin{array}{l}\text { Perdas } \\
\text { Totais }\end{array}$ \\
\hline Umidade & 1 & $0,000115^{\mathrm{ns}}$ & $0,057201 * *$ & $0,005975 * *$ & $0,061339 * *$ & $0,062026 * *$ \\
\hline Velocidade & 2 & $0,000060^{\mathrm{ns}}$ & $0,012352 * *$ & $0,000149^{\mathrm{ns}}$ & $0,012068 * *$ & $0,011908 * *$ \\
\hline Interação & 2 & $0,000417^{\mathrm{ns}}$ & $0,002084^{\mathrm{ns}}$ & $0,000086^{\mathrm{ns}}$ & $0,001967^{\mathrm{ns}}$ & $0,001834^{\mathrm{ns}}$ \\
\hline Blocos & 5 & - & - & - & - & - \\
\hline Resíduo & 25 & - & - & - & - & - \\
\hline C.V. (\%) & - & 90,29 & 23,08 & 88,40 & 22,82 & 22,57 \\
\hline
\end{tabular}

Pelos resultados apresentados na Tabela 2, verifica-se que a colheita realizada com a colhedora C2 e com grau de umidade de $16 \%$ apresentou menores perdas na separação e limpeza, trilha, separação e limpeza mais trilha e perdas totais do que quando a operação foi realizada com grãos contendo $22 \%$ de umidade. Em relação às perdas totais, esses resultados estão de acordo com aqueles observados por PORTELLA (2003), que concluiu que, na medida em que os grãos secam 
na lavoura, melhora o desempenho da colhedora, tanto na plataforma quanto nos mecanismos internos (trilha e separação), fato também apontado por SGARBI (2006).

TABELA 2. Perdas percentuais de acordo com o grau de umidade dos grãos e da velocidade de deslocamento das colhedoras. Losses according to grain moisture and harvesting speed.

\begin{tabular}{|c|c|c|c|c|c|c|c|}
\hline & \multirow[t]{2}{*}{ Perdas $(\%)$} & \multirow[t]{2}{*}{$\begin{array}{l}\text { C.V. } \\
(\%)\end{array}$} & \multicolumn{2}{|c|}{$\begin{array}{c}\text { Grau de Umidade } \\
(\%)\end{array}$} & \multicolumn{3}{|c|}{$\begin{array}{l}\text { Velocidade de Deslocamento } \\
\left(\mathrm{m} \mathrm{s}^{-1}\right)\end{array}$} \\
\hline & & & 16 & 22 & 0,53 & 0,77 & 1,42 \\
\hline \multirow{6}{*}{$\begin{array}{l}\text { Colhedora } \\
\text { (C1) }\end{array}$} & Plataforma & 133,67 & $0,00 \mathrm{a}$ & $0,00 \mathrm{a}$ & $0,00 \mathrm{a}$ & $0,00 \mathrm{a}$ & $0,00 \mathrm{a}$ \\
\hline & Separação e limpeza & 40,11 & $1,10 \mathrm{a}$ & $1,49 \mathrm{a}$ & $1,51 \mathrm{a}$ & $1,10 \mathrm{a}$ & $1,27 \mathrm{a}$ \\
\hline & Trilha & ** & $0,00 \mathrm{a}$ & $0,01 \mathrm{a}$ & $0,00 \mathrm{a}$ & $0,00 \mathrm{a}$ & $0,01 \mathrm{a}$ \\
\hline & Separação e limpeza + trilha & 41,93 & $1,10 \mathrm{a}$ & $1,53 \mathrm{a}$ & $1,53 \mathrm{a}$ & $1,10 \mathrm{a}$ & $1,30 \mathrm{a}$ \\
\hline & Totais & 41,87 & $1,10 \mathrm{a}$ & $1,67 \mathrm{a}$ & $1,53 \mathrm{a}$ & $1,11 \mathrm{a}$ & $1,30 \mathrm{a}$ \\
\hline & Perdas $(\%)$ & C.V. & 16 & 22 & 0,59 & 0,85 & 1,52 \\
\hline \multirow{5}{*}{$\begin{array}{l}\text { Colhedora } \\
\text { (C2) }\end{array}$} & Plataforma & 90,29 & $0,01 \mathrm{a}$ & $0,02 \mathrm{a}$ & $0,01 \mathrm{a}$ & $0,01 \mathrm{a}$ & $0,01 \mathrm{a}$ \\
\hline & Separação e limpeza & 23,08 & $1,93 \mathrm{a}$ & $4,72 \mathrm{~b}$ & $4,41 \mathrm{~b}$ & $3,14 \mathrm{ab}$ & $2,16 \mathrm{a}$ \\
\hline & Trilha & 88,40 & $0,01 \mathrm{a}$ & $0,11 \mathrm{~b}$ & $0,05 \mathrm{a}$ & $0,03 \mathrm{a}$ & $0,05 \mathrm{a}$ \\
\hline & Separação e limpeza + trilha & 22,82 & $1,95 \mathrm{a}$ & $4,87 \mathrm{~b}$ & $4,51 \mathrm{~b}$ & $3,18 \mathrm{ab}$ & $2,25 \mathrm{a}$ \\
\hline & Totais & 22,57 & $1,96 \mathrm{a}$ & $4,91 \mathrm{~b}$ & $4,53 \mathrm{~b}$ & $3,20 \mathrm{ab}$ & $2,28 \mathrm{a}$ \\
\hline
\end{tabular}

$\overline{\text { Médias seguidas }}$ de mesma letra na linha não diferem entre si, pelo Teste de Tukey, a $5 \%$ de significância. ** na $\overline{\text { quantificação de }}$ perdas de trilha, não houve dados suficientes para a análise, demonstrando a eficiência da colhedora nessa variável.

Em relação à velocidade de deslocamento, foram observadas menores perdas de separação e limpeza, separação e limpeza mais trilha e perdas totais nas velocidades $1,52 \mathrm{~m} \mathrm{~s}^{-1}$ e $0,85 \mathrm{~m} \mathrm{~s}^{-1}$, respectivamente, não diferindo estatisticamente entre si. As maiores perdas foram observadas quando a colheita foi conduzida na menor velocidade $\left(0,59 \mathrm{~m} \mathrm{~s}^{-1}\right)$. Os resultados corroboram aqueles encontrados por LIMA et al. (2007), que também encontraram menores perdas com o aumento da velocidade de deslocamento. Em concordância com os resultados encontrados sobre perdas totais, MELLO (2006), utilizando colhedora automotriz, observou que as médias percentuais de perdas totais decresciam com o aumento da velocidade de deslocamento da colhedora: $0,99 \%$ na velocidade de $1,50 \mathrm{~m} \mathrm{~s}^{-1}, 0,96 \%$ na velocidade de $1,88 \mathrm{~m} \mathrm{~s}^{-1}$ e $0,46 \%$ na velocidade de $2,72 \mathrm{~m} \mathrm{~s}^{-1}$. Por outro lado, segundo KYDD (1980), as perdas, via de regra, crescem com o aumento da taxa de alimentação em colhedoras automotrizes. Contudo, SILVA et al. (2004), utilizando colhedora automotriz com sistema de fluxo axial, constataram que a velocidade de deslocamento influencia de forma significativa nas perdas de grãos de milho com colhedoras operando em faixas de velocidade de $1,11 \mathrm{a} 1,67 \mathrm{~m} \mathrm{~s}^{-1}$, apresentando perdas superiores às encontradas em máquinas com velocidades superiores a $1,94 \mathrm{~m} \mathrm{~s}^{-1}$.

De acordo com os resultados das análises de variância apresentados na Tabela 3 , houve influência do fator umidade e interação entre os fatores no parâmetro falhas na germinação para a colhedora $\mathrm{C} 1$. No fator velocidade, houve efeito significativo somente para impureza nos grãos. Na colhedora $\mathrm{C} 2$, houve efeito significativo do fator grau de umidade dos grãos somente em falhas de germinação e interação entre os fatores testados em danos mecânicos.

Nos resultados apresentados na Tabela 4, observa-se, na colhedora $\mathrm{C} 1$, que a velocidade de deslocamento de $0,53 \mathrm{~m} \mathrm{~s}^{-1}$ foi a que apresentou a menor percentagem de impurezas, seguido pela velocidade de $0,77 \mathrm{~m} \mathrm{~s}^{-1}$, as quais não diferiram estatisticamente entre si. A maior ocorrência de impurezas foi encontrada na maior velocidade de deslocamento $\left(1,42 \mathrm{~m} \mathrm{~s}^{-1}\right)$. Esses resultados indicam que, com o aumento da velocidade de deslocamento, há elevação no fluxo de massa em relação ao fluxo de ar, interferindo na eficiência do sistema de separação e limpeza dos grãos, que apresentou maiores percentagens de impureza com a elevação da velocidade.

Com relação às falhas na germinação, em ambas as colhedoras, o grau de umidade dos grãos de $16 \%$ foi o que apresentou os melhores resultados em comparação ao grau de umidade de $22 \%$. 
TABELA 3. Análise de variância de impureza nos grãos, danos mecânicos e falhas na germinação de colhedoras de uma e duas fileiras. Analysis of variance of grain impurity, mechanical damages and germination failures for the one and two rows harvesters.

\begin{tabular}{|c|c|c|c|c|}
\hline \multirow{2}{*}{ F.V. (1) } & \multirow{2}{*}{$\begin{array}{l}\text { G.L. } \\
\text { (2) }\end{array}$} & \multicolumn{3}{|c|}{ Quadrados Médios - C1 } \\
\hline & & Impureza & Danos Mecânicos & Falhas na Germinação \\
\hline Umidade & 1 & $0,000374^{\mathrm{ns}}$ & $0,008516^{\mathrm{ns}}$ & $0,034163 *$ \\
\hline Velocidade & 2 & $0,004335 *$ & $0,003481^{\mathrm{ns}}$ & $0,001395^{\mathrm{ns}}$ \\
\hline Interação & 2 & $0,000656^{\mathrm{ns}}$ & $0,000800^{\mathrm{ns}}$ & $0,042556 * *$ \\
\hline Blocos & 5 & - & - & - \\
\hline$\underline{\text { Resíduo }}$ & 25 & - & - & - \\
\hline C.V. $(\%)$ & - & 53,62 & 10,08 & 19,17 \\
\hline \multirow{2}{*}{ F.V. (1) } & G.L. & \multicolumn{3}{|c|}{ Quadrados Médios - C2 } \\
\hline & $(2)$ & Impureza & Danos Mecânicos & Falhas na Germinação \\
\hline Umidade & 1 & $0,000376^{\mathrm{ns}}$ & $0,003977^{\mathrm{ns}}$ & $0,028420 *$ \\
\hline Velocidade & 2 & $0,000126^{\mathrm{ns}}$ & $0,000635^{\mathrm{ns}}$ & $0,003869^{\mathrm{ns}}$ \\
\hline Interação & 2 & $0,000300^{\mathrm{ns}}$ & $0,010585 *$ & $0,011882^{\mathrm{ns}}$ \\
\hline Blocos & 5 & - & - & - \\
\hline Resíduo & 25 & - & - & - \\
\hline C.V. $(\%)$ & - & 48,98 & 11,91 & 24,29 \\
\hline
\end{tabular}

TABELA 4. Parâmetros percentuais de qualidade, de acordo com a umidade dos grãos e velocidade de deslocamento das colhedoras. Quality parameters according to grain moisture and harvesters speed.

\begin{tabular}{|c|c|c|c|c|c|c|c|}
\hline & \multirow{2}{*}{$\begin{array}{l}\text { Parâmetros de } \\
\text { Qualidade }(\%)\end{array}$} & \multirow[t]{2}{*}{$\begin{array}{l}\text { C.V. } \\
(\%)\end{array}$} & \multicolumn{2}{|c|}{$\begin{array}{c}\text { Grau de Umidade } \\
(\%)\end{array}$} & \multicolumn{3}{|c|}{$\begin{array}{l}\text { Velocidade de Deslocamento } \\
\qquad\left(\mathrm{m} \mathrm{s}^{-1}\right)\end{array}$} \\
\hline & & & 16 & 22 & 0,53 & 0,77 & 1,42 \\
\hline \multirow{4}{*}{$\begin{array}{l}\text { Colhedora } \\
\text { (C1) }\end{array}$} & Impureza & 53,62 & $0,36 \mathrm{a}$ & $0,44 \mathrm{a}$ & $0,24 \mathrm{a}$ & $0,31 \mathrm{ab}$ & $0,72 \mathrm{~b}$ \\
\hline & Danos mecânicos & 10,08 & $21,91 \mathrm{a}$ & $24,50 \mathrm{a}$ & $23,95 \mathrm{a}$ & $21,55 \mathrm{a}$ & $24,10 \mathrm{a}$ \\
\hline & Falhas na germinação & 19,17 & $9,76 \mathrm{a}$ & $13,72 b$ & $11,39 \mathrm{a}$ & $11,16 \mathrm{a}$ & $12,47 \mathrm{a}$ \\
\hline & Parâmetros de Qualidade (\%) & C.V. & 16 & 22 & 0,59 & 0,85 & 1,52 \\
\hline \multirow{3}{*}{$\begin{array}{l}\text { Colhedora } \\
\text { (C2) }\end{array}$} & Impureza & 48,98 & $0,20 \mathrm{a}$ & $0,26 \mathrm{a}$ & $0,23 \mathrm{a}$ & $0,20 \mathrm{a}$ & $0,26 \mathrm{a}$ \\
\hline & Danos mecân & 11,91 & $13,40 \mathrm{a}$ & 13,99 a & $14,69 \mathrm{a}$ & 13,99 a & $13,71 \mathrm{a}$ \\
\hline & Falhas na germinação & 24,29 & $8,01 \mathrm{a}$ & $11,32 \mathrm{~b}$ & $9,33 \mathrm{a}$ & $8,73 \mathrm{a}$ & $10,81 \mathrm{a}$ \\
\hline
\end{tabular}

Médias seguidas de mesma letra na linha não diferem entre si, pelo Teste de Tukey, a 5\% de significância.

No desdobramento do grau de umidade dos grãos dentro das três velocidades de deslocamento (Tabela 5), constatou-se que a umidade de $16 \%$ foi a que apresentou o menor dano mecânico aos grãos na velocidade de $0,59 \mathrm{~m} \mathrm{~s}^{-1}$. O mesmo não ocorre nas demais velocidades, em que não houve diferenças significativas para os dois graus de umidade ensaiados, dentro de cada velocidade. No desdobramento velocidade de deslocamento dentro dos dois graus de umidade dos grãos, observa-se, pela Tabela 5, que as velocidades de $1,52 \mathrm{~m} \mathrm{~s}^{-1}$ e $0,85 \mathrm{~m} \mathrm{~s}^{-1}$ apresentaram os menores danos, na condição de grau de umidade de $22 \%$, não diferindo entre si pelo teste de Tukey, a $5 \%$ de significância. A menor velocidade de deslocamento $\left(0,59 \mathrm{~m} \mathrm{~s}^{-1}\right)$ foi a que apresentou o maior dano mecânico.

Constatações de CARVALHO \& NAKAGAWA (1988) indicam que os impactos mecânicos são acumulativos e, quanto menor os graus de umidade dos grãos no momento da colheita, menores são os danos sofridos pelas sementes de milho, o que não condiz com os resultados reportados por RUFFATO et al. (2001), que relatam que quanto mais seco se encontra o grão, menor a elasticidade de sua película protetora, tornando-o mais vulnerável aos danos provenientes da ação dos 
equipamentos. A colhedora de uma fileira não apresentou efeito significativo para a interação grau de umidade dos grãos e velocidade de deslocamento.

TABELA 5. Resumo dos resultados dos desdobramentos do grau de umidade dos grãos e velocidade de deslocamento para percentagem de danos mecânicos aos grãos na colhedora $\mathrm{C} 2$. Results of grain moisture and harvester speed to grain mechanical damages for the $\mathrm{C} 2$ harvester.

\begin{tabular}{cccc}
\hline \multirow{2}{*}{ Umidade } & \multicolumn{3}{c}{ Velocidade $\left(\mathrm{m} \mathrm{s}^{-1}\right)$} \\
\cline { 2 - 4 } & 0,59 & 0,85 & 1,52 \\
\hline $16 \%$ & $11,67 \mathrm{aA}$ & $14,59 \mathrm{aA}$ & $14,02 \mathrm{aA}$ \\
$22 \%$ & $18,00 \mathrm{bB}$ & $13,39 \mathrm{aA}$ & $13,39 \mathrm{aA}$ \\
\hline
\end{tabular}

Médias seguidas de mesma letra, minúscula nas linhas e maiúscula nas colunas, não diferem entre si, pelo teste de Tukey, a 5\% de significância.

No desdobramento do grau de umidade dos grãos dentro das três velocidades de deslocamento, pode-se observar que, nas velocidades de $0,53 \mathrm{~m} \mathrm{~s}^{-1}$ e $0,77 \mathrm{~m} \mathrm{~s}^{-1}$, houve efeitos dos tratamentos para as duas umidades ensaiadas dentro de cada velocidade; em ambas as velocidades, a umidade de $16 \%$ foi a que apresentou a menor falha de germinação (Tabela 6).

TABELA 6. Resumo dos resultados dos desdobramentos do grau de umidade dos grãos e da velocidade de deslocamento para os dados de perdas percentuais por falhas de germinação na colhedora $\mathrm{C} 1$. Results of grain moisture and harvester speed to germination failures for the $\mathrm{C} 1$ harvester.

\begin{tabular}{lccc}
\hline \multirow{2}{*}{ Interação } & \multicolumn{4}{c}{ Velocidade $\left(\mathrm{m} \mathrm{s}^{-1}\right)$} \\
\cline { 2 - 4 } & 6,53 & 0,77 & 1,42 \\
\hline Umidade de 16\% & 6,87 a A & 8,25 a A & 14,93 a B \\
Umidade de 22\% & 16,86 b B & 14,45 b AB & 10,20 a A \\
\hline $\begin{array}{l}\text { Médias seguidas de mesma letra, minúscula nas linhas e maiúscula nas colunas, não diferem entre si, pelo teste de } \\
\text { Tukey, a 5\% de significância. }\end{array}$
\end{tabular}

Em relação ao desdobramento da velocidade de deslocamento dentro das duas umidades dos grãos, verifica-se que, em ambos os desdobramentos, ocorreram efeitos dos tratamentos (Tabela 6). Com relação ao grau de umidade de $16 \%$, verifica-se, pela Tabela 6 , que as menores falhas de germinação ocorreram nas velocidades de $0,53 \mathrm{~m} \mathrm{~s}^{-1}$ e $0,77 \mathrm{~m} \mathrm{~s}^{-1}$, e, no grau de umidade de $22 \%$, a velocidade de $1,42 \mathrm{~m} \mathrm{~s}^{-1}$ foi a que apresentou o menor percentual de falhas de germinação, superando as outras duas velocidades de deslocamento que não variaram estatisticamente entre si.

\section{CONCLUSÕES}

O método de ensaio adotado é efetivo para a avaliação do desempenho de colhedoras semimontadas; o sistema desenvolvido para a coleta de material é eficiente, porém demanda a disponibilidade de muitos colaboradores.

As perdas de separação e limpeza, trilha, bem como as perdas totais na traseira das colhedoras são menores quando a colheita é realizada com a lavoura de milho com grãos contendo o menor grau de umidade $(16 \%)$ na maior velocidade de deslocamento adotada $\left(1,52 \mathrm{~m} \mathrm{~s}^{-1}\right)$, para a colhedora de duas fileiras. Já a colhedora de uma fileira não sofreu influência de nenhum dos fatores dentro dos intervalos estudados, apresentando perda total média inferior a 1,40\%.

Os teores de impurezas são maiores quando a colheita é executada com velocidades de deslocamento mais elevadas, tanto em lavoura com $16 \%$ de umidade dos grãos como naquelas com $22 \%$ de umidade, para ambas as colhedoras. 
Não há diferença nos índices de danos mecânicos nos grãos colhidos com a colhedora de uma fileira, nas operações de colheita realizadas com grãos em grau de umidade de 16 e $22 \%$, e com velocidades de $0,53 \mathrm{~m} \mathrm{~s}^{-1}$ a $1,42 \mathrm{~m} \mathrm{~s}^{-1}$. Já a colhedora de duas fileiras apresentou melhores resultados com o grau de umidade dos grãos de $16 \%$ na menor velocidade de deslocamento $\left(0,59 \mathrm{~m} \mathrm{~s}^{-1}\right)$.

Os grãos colhidos pela colhedora C2 apresentaram maior poder germinativo com a colheita realizada com os grãos contendo o menor grau de umidade adotado (16\%), independentemente da velocidade de deslocamento. Já a colhedora $\mathrm{C} 1$ obteve menores falhas de germinação quando operou na menor velocidade de deslocamento $\left(0,53 \mathrm{~m} \mathrm{~s}^{-1}\right)$ e com o menor grau de umidade (16\%), bem como na maior velocidade $\left(1,42 \mathrm{~m} \mathrm{~s}^{-1}\right)$ e com o maior grau de umidade $(22 \%)$.

\section{REFERÊNCIAS}

ABNT. ASSOCIAÇÃO BRASILEIRA DE NORMAS TÉCNICAS. NBR 9740: colhedora autopropelida de grãos - determinação das características técnicas e de desempenho. Rio de Janeiro, 1987. $13 \mathrm{p}$.

BALASTREIRE, L.A. Máquinas agrícolas. São Paulo: Manole, 1987. 309 p.

BEDUSCHI, L.C. Estudo operacional e econômico de dois sistemas mecanizados de colheita de milho (Zea mays L.). 1986. 164 f. Tese (Livre-Docência) - Faculdade de Ciências Agrárias e Veterinárias de Jaboticabal, Universidade Estadual Paulista “Júlio de Mesquita Filho", Jaboticabal, 1986.

BRASIL. Ministério da Agricultura, do Abastecimento e da Reforma Agrária. Regras para análise de sementes. Brasília, 1992. 365 p.

CARVALHO, N.M. de; NAKAGAWA, J. Sementes: ciência, tecnologia e produção. 3.ed.

Campinas: Fundação Cargill, 1988. 424 p.

CIMILHO. Disponível em: http://cimilho.cnpms.embrapa.br/mostranoticia.php?codigo=70> Acesso em: 12 dez. 2007.

CONAB. COMPANHIA NACIONAL DE ABASTECIMENTO. Disponível em: <http://www.conab.gov.br/conabweb/download/safra/estudo_safra.pdf> Acesso em: 26 dez. 2007. FERREIRA, D.F. Manual do sistema Sisvar para análises estatísticas. Lavras: UFLA, 2000. 66 p.

KYDD, H.D. Measuring combine capacity. PAMI - Prairie Agricultural Machinery Institute, 1980. Disponível em:

<http://www1.agric.gov.ab.ca/\$department/deptdocs.nsf/ba3468a2a8681f69872569d60073fde1/a9b 9bcc4fc6ba76187256e040062421f/\$FILE/157.PDF>. Acesso em: 12 mar. 2007.

LIMA, C.M.; MOLIN, J.P.; ARAÚJO, J.C.; FLEMING, W.; PEREIRA, A.J. Avaliação do desempenho de uma colhedora semimontada para colheita mecanizada direta de milho. In: CONGRESSO BRASILEIRO DE ENGENHARIA AGRÍCOLA, 36., 2007, Bonito. Anais ... Jaboticabal: Associação Brasileira de Engenharia Agrícola, 2007. 1 CD-ROM.

MELLO, A.J.R. Produtividade e perdas na colheita de dois cultivares híbridos de milho em função da velocidade de semeadura (Zea mays L.). 2006. 65 f. Tese (Mestrado em Ciência do Solo) Faculdade de Ciências Agrárias e Veterinária, Universidade Estadual Paulista "Júlio de Mesquita Filho", Jaboticabal, 2006.

MIALHE, L.G. Máquinas para colher cereais. Piracicaba: ESALQ, 1984. 66 p.

PORTELLA, J.A. Influência do ponto de colheita nas perdas de grãos de milho. In: CONGRESSO BRASILEIRO DE ENGENHARIA AGRÍCOLA, 32., 2003, Goiânia. Anais ... Goiânia: Associação Brasileira de Engenharia Agrícola, 2003. 1 CD-ROM. 
PRADO, H. do. Solos do Brasil. 4.ed. Piracicaba: Ceres, 2005. 281 p.

RUFFATO, S.; COUTO, S.M.; QUEIROZ, D.M. Análise de impacto em grãos de milho pelo método de elementos finitos. Revista Brasileira de Armazenamento, Viçosa, v.26, n.1, p.21-7, 2001.

SATO, O. Efeito da seleção de espigas e da debulha na qualidade física e fisiológica das sementes de milho (Zea mays, L.). 1991. 110 f. Dissertação (Mestrado em Fitotecnia) - Escola Superior de Agricultura "Luiz de Queiroz", Universidade de São Paulo, Piracicaba, 1991.

SGARBI, V.P. Perdas na colheita de milho (Zea mays L.) em função da rotação do cilindro trilhador e umidade dos grãos. 2006. 33 f. Monografia (Graduação em Agronomia) - Faculdade de Ciências Agrárias e Veterinárias, Universidade Estadual Paulista "Júlio de Mesquita Filho", Jaboticabal, 2006.

SILVA, R.P.; CAMPOS, M.A.O.; MESQUITA, H.C.B.; ZABANI, S. Perdas na colheita mecanizada de milho no Triângulo Mineiro e Alto Paranaíba-MG. Fazu em Revista, Uberaba, v.1, n.1, p.3-10, 2004.

SOUZA, C.M.A.; RAFULL, L.Z.L.; REIS, E.F.; SOBRINHO, T.A. Perdas na colheita mecanizada de milho em agricultura familiar da Zona da Mata Mineira. Revista Brasileira de Milho e Sorgo, Sete Lagoas, v.5, n.2, p.280-90, 2006.

SRIVASTAVA, A.K.; GOERING, C.E.; ROHRBACH, R.P. Engineering principles of agricultural machines. St. Joseph: ASAE, 1993. 601 p. (Series, 6). 